Rev. Bras. Saúde Prod. Anim., Salvador, v.13, n.3, p.815-824 jul./set., 2012 http://www.rbspa.ufba.br ISSN 15199940

\title{
Propriedades físicas e sensoriais da carne suína PSE
}

\author{
Physical and sensory properties of PSE pork
}

\section{CALDARA, Fabiana Ribeiro $^{1 *}$; SANTOS, Viviane Maria Oliveira $\operatorname{dos}^{1}$; SANTIAGO, Juliana Cascão ${ }^{1}$; ALMEIDA PAZ, Ibiara Correia de Lima ${ }^{1}$; GARCIA, Rodrigo Garófallo $^{1}$; VARGAS JUNIOR, Fernando Miranda de ${ }^{1}$; SANTOS, Luan Sousa dos ${ }^{1}$; NÄÄS, Irenilza de Alencar ${ }^{1}$}

\author{
${ }^{1}$ Universidade Federal da Grande Dourados, Faculdade de Ciências Agrárias, Dourados, Mato Grosso do \\ Sul, Brasil. \\ *Endereço para correspondência: fabianacaldara@ufgd.edu.br
}

\section{RESUMO}

Objetivou-se avaliar as características físicas e sensoriais da carne suína PSE, suas correlações e os prejuízos causados para a indústria, em função de sua ocorrência. Em abatedouro comercial aferiu-se o pH das carcaças $(\mathrm{n}=1601)$ aos 45 minutos post mortem $\left(\mathrm{pH}_{45}\right)$, classificou-as em PSE $\left(\mathrm{pH}_{45}<5,8\right)$ ou normais $\left(\mathrm{pH}_{45} \geq 5,8\right)$. Após 24 horas de resfriamento, foram coletadas amostras do músculo Longissimus dorsi de 26 carcaças PSE e 26 normais, que foram avaliadas quanto à coloração ( $\left.L^{*}, a^{*}, b^{*}\right)$, perda de exsudato, perda de peso por cozimento, força de cisalhamento, atributos sensoriais (maciez, suculência e palatabilidade) e composição centesimal. Foram avaliadas as correlações entre parâmetros físicos e sensoriais. A incidência de carnes PSE foi de $10,06 \%$. O pH final, perda de peso por cozimento, força de cisalhamento e composição centesimal não diferiram entre os tipos de carne. A perda de exsudato foi, aproximadamente, $39 \%$ maior para carne PSE. O $\mathrm{pH}_{45}$ correlacionou-se, negativamente, com $\mathrm{L}^{*}(\mathrm{R}=-0,331)$ e $\mathrm{b}^{*}$ $(\mathrm{R}=-0,528)$. A suculência correlacionou-se, positivamente, com a palatabilidade $(\mathrm{R}=0,436) \mathrm{e}$ maciez $(\mathrm{R}=0,297) \mathrm{e}$, negativamente, com a perda de peso por cozimento $(R=-0,326)$. A força de cisalhamento apresentou correlação positiva com perda de exsudato $(R=0,529)$ e negativa com maciez $(\mathrm{R}=-0,767)$. O prejuízo estimado em função da ocorrência de carnes PSE foi da ordem de $\mathrm{R} \$ 340.800,00$ anuais. Carnes PSE apresentam alterações negativas nas propriedades funcionais $\mathrm{e}$ sensoriais, relacionadas com a redução de sua capacidade de retenção de água, o que causa perdas consideráveis para a indústria processadora.

Palavras-chave: capacidade de retenção de água, coloração, exsudação, pH, suínos.

\section{SUMMARY}

The work was carried out to evaluate the physical and sensory characteristics of PSE pork, their correlations and damages caused to the industry because of its occurrence. In a commercial slaughterhouse has measured the $\mathrm{pH}$ of carcasses $(\mathrm{n}=1601)$ at 45 minutes post mortem $\left(\mathrm{pH}_{45}\right)$, classified them into PSE $\left(\mathrm{pH}_{45}<\right.$ $5.8)$ or normal $\left(\mathrm{pH}_{45} \geq 5.8\right)$. After 24 hours of cooling were collected the samples from the Longissimus dorsi muscle of the 26 normal and 26 PSE carcasses that were evaluated for color $\left(\mathrm{L}^{*}, \mathrm{a}^{*}, \mathrm{~b}^{*}\right)$, exudate loss, cooking loss, shear force, sensory attributes (tenderness, juiciness and flavor) and centesimal composition. Were evaluated the correlations between the physical and sensory parameters. The final $\mathrm{pH}$, cooking loss, shear force and centesimal composition did not differ between the types of meat. The exudate loss was 39\% higher for the PSE meat. The $\mathrm{pH}_{45}$ was negatively correlated with $\mathrm{L}^{*}$ $(\mathrm{R}=-0.331)$ and $\mathrm{b} *(\mathrm{R}=-0.528)$. The juiciness was positively correlated with flavor $(r=0.436)$ and tenderness $(R=0.297)$ and negatively with cooking loss $(R=-0.326)$. The shear force was positively correlated with exudate loss $(\mathrm{R}=0.529)$ and negatively with tenderness $(\mathrm{R}=-0.767)$. The estimated loss due to the occurrence of PSE meat were of R $\$ 340,800.00$ per year. The PSE meat show negative changes in the functional and sensory properties, almost all related to reducing its water holding capacity, causing considerable losses to the processing industry.

Keywords: color, exudation, $\mathrm{pH}$, swine, water holding capacity. 


\section{INTRODUÇÃOO}

A partir da década de 60 , por exigência do mercado consumidor, houve o direcionamento do trato de suínos para o aumento na produção de carne magra, o que acarretou modificações substanciais na composição e nas características bioquímicas do músculo. Posteriormente, constatou-se que as principais alterações bioquímicas foram provocadas por uma mutação genética na proteína reguladora do fluxo de cálcio, rianodina, de modo a provocar o surgimento da Síndrome do Estresse Porcino (PSS- Pork Stress Syndrome) (MAGANHINI et al., 2007). $\mathrm{O}$ gene halotano, além de determinar a maior predisposiçãao a PSS, é responsável por carcaças com maior proporção de carne magra, mas relacionado à produção de carne PSE (pale, soft and exudative) um problema grave para a industrialização de carnes (SATHER et al., 1991).

Uma vez que esse novo modelo animal tornou-se mais sensível ao estresse, fatores envolvidos no período pré-abate podem influenciar, negativamente, seu bem-estar e, consequentemente, a qualidade da carne (PÉREZ et al., 2002ab; COSTA et al., 2009), o que aumenta de forma significativa a incidência de carne PSE.

O desenvolvimento da carne PSE é resultado da elevação da taxa glicolítica, imediatamente antes e logo após o abate, o que acarreta maior concentração de ácido lático e decréscimo acelerado do $\mathrm{pH}$ muscular. A combinação do $\mathrm{pH}$ baixo e elevada temperatura da carcaça levam a maior desnaturação de proteínas miofibrilares com consequente redução em sua capacidade de retenção de água. Esse tipo de carne representa um problema sério para a indústria, já que sua perda excessiva de exsudato, extrema flacidez e ausência de cor, além de serem rejeitadas pelos consumidores, prejudicam os processos industriais de fabricação (D'SOUZA et al., 1998).

As características de qualidade mais importantes da carne, que determinam a aceitação global do corte, são a aparência (cor, brilho e apresentação do corte), responsável pela aceitação do consumidor no momento da compra, e a maciez percebida na degustação (ARGUELO, 2005). O grau de qualidade varia segundo o ponto de vista e interesse do produtor, da indústria, do comércio e principalmente do consumidor (DABÉS, 2001; SIQUEIRA et al., 2002)

Assim, julgou-se importante avaliar as características físicas e sensoriais da carne PSE de suínos, bem como as correlações existentes entre elas e estimar os prejuízos à indústria, provenientes da ocorrência dessa anomalia.

\section{MATERIAL E MÉTODOS}

O experimento foi conduzido na Universidade Federal da Grande Dourados, Dourados, MS. As amostras de carne utilizadas na pesquisa foram obtidas em abatedouro comercial, situado no mesmo município, com capacidade de abate de, aproximadamente, 2300 cabeças por dia, número que representa cerca de $50 \%$ do abate do estado. Para seleção e coleta das amostras foram realizadas duas visitas a um abatedouro comercial, quando os suínos, todos da mesma linhagem genética (TOPIGS), selecionada para alta deposição de carne magra na carcaça, foram abatidos com peso vivo médio de $115 \mathrm{~kg}$, conforme o protocolo de abate convencional após insensibilização por eletronarcose O manejo pré-abate foi padronizado para todos os animais. O tempo de jejum efetivo anterior ao transporte foi de aproximadamente seis horas. Os 
animais mais pesados de cada baia eram selecionados para embarque, e a condução realizada com auxílio de tábuas de manejo, dessa forma, acontecia a mistura de lotes a partir desse momento. Os animais foram molhados e embarcados por meio de rampas elevadiças até a carroceria do caminhão, com densidade de transporte padronizada entre 250 a $280 \mathrm{~kg}$ de peso vivo por $\mathrm{m}^{2}$. O transporte perfazia uma distância média de $100 \mathrm{~km}$, em, aproximadamente, 1 hora e 30 minutos. Após o desembarque, os animais foram encaminhados à pocilga de descanso e foram alojados em densidade de $0,65 \mathrm{~m}^{2} /$ animal. Cumprido o período de descanso, de aproximadamente seis horas, foram guiados ao abate, por meio de tábuas de manejo até a seringa e, só então, foi utilizado o bastão elétrico para que o animal entrasse na esteira rolante. Após a insensibilização por eletronarcose, foram abatidos conforme procedimento padrão, com sangria realizada na posição horizontal e as carcaças submetidas ao escaldamento, depilação, toilete, evisceração, serragem e inspeção.

Aos 45 minutos após o abate $\left(\mathrm{pH}_{45}\right)$, foram avaliados o $\mathrm{pH}$ de 1601 carcaças suínas. A mensuração do $\mathrm{pH}_{45}$ nas carcaças foi realizada por método direto, com peagâmetro portátil, acoplado a uma sonda com ponta fina de penetração, inserida no centro do músculo Longissimus dorsi, da meia carcaça esquerda, entre a $12^{\mathrm{a}}$ e $13^{\mathrm{a}}$ vértebra torácica. Concomitantemente à avaliação do $\mathrm{pH}_{45}$ e $\mathrm{pH}_{24}$, foram registradas as temperaturas das carcaças, por meio de um termômetro de inserção digital. Carcaças com valores de $\mathrm{pH}_{45}<5,8$ foram classificadas como PSE e aquelas com $\mathrm{pH} \geq 5,8$ como normais (ORDOÑEZ et al., 1998; VELAZCO, 2001). A incidência total de carne PSE foi obtida com a utilização da quantidade de animais positivos para PSE $\left(\mathrm{pH}_{45}<5,8\right)$ em relação ao número total de animais avaliados, expressa em porcentagem.

Para coleta de amostras, foram selecionadas 26 carcaças diagnosticadas como PSE e 26 normais que, após 24 horas de resfriamento em câmara frigorífica (entre 2 e $4^{\circ} \mathrm{C}$ ), foram novamente avaliadas quanto ao $\mathrm{pH}$ $\left(\mathrm{pH}_{24}\right)$, desossadas e extraídas amostras da meia carcaça esquerda do músculo Longissimus dorsi entre a $12^{\mathrm{a}}$ e $13^{\mathrm{a}}$ vértebra torácica.

Para avaliação da coloração, as amostras cortadas em bifes de aproximadamente $2,5 \mathrm{~cm}$ de espessura foram expostas ao ar, durante 30 minutos, para, então, serem submetidas à avaliação objetiva da cor. Tal avaliação foi desenvolvida por meio de um colorímetro portátil modelo Minolta CR 410, utilizando-se a escala luminosidade $\left(\mathrm{L}^{*}\right)$, intensidade de vermelho $\left(\mathrm{a}^{*}\right)$ e intensidade de amarelo (b*) do sistema CIELAB, com fonte de luz de D65 e ângulo de $10^{\circ}$. As medidas foram realizadas em três pontos distintos na superfície da amostra, a tomar a média como o valor determinado.

Amostras de $2,5 \mathrm{~cm}$ de espessura provenientes do músculo Longissimus dorsi foram pesadas em balança semianalítica e utilizadas para avaliação da perda de exsudato (PE) e perda de peso por cozimento (PPC). Para avaliação da perda de exsudato, as amostras foram acondicionadas em bandejas plásticas, envoltas por filme plástico PVC e mantidas sob simulação de venda ao varejo a $4 \pm 1^{\circ} \mathrm{C}$ por 48 horas. Decorrido esse tempo, foram novamente pesadas e a perda de exsudato foi expressa em percentual do peso inicial da amostra. Para mensuração da perda de peso por cozimento, as amostras foram assadas em forno elétrico a $300^{\circ} \mathrm{C}$, até atingirem a temperatura interna média de $80^{\circ} \mathrm{C}$, observada por meio de um termômetro digital de espeto, inserido no centro da amostra. Após cozimento, as amostras 
foram resfriadas à temperatura ambiente por uma hora e mais uma vez pesadas, expressando-se a PPC em percentual do peso inicial da amostra.

Das amostras assadas para avaliação da perda de peso por cozimento, foram retirados seis cilindros de $13 \mathrm{~mm}$ de diâmetro, no sentido paralelo às fibras musculares, com auxílio de um vazador. A força de cisalhamento da carne foi mensurada por meio de um Texturômetro (mod. TA.XT2i, marca Stable Micro Systems), com lâmina Warner-Bratzler, que deslocava-se à velocidade de descida de 500 mm $/ \mathrm{min}$ (AMSA, 1995).

Foram realizadas cinco sessões de avaliação sensorial da carne para os parâmetros maciez, palatabilidade $\mathrm{e}$ suculência, por um painel de cinco degustadores treinados. Estes atribuíram valores de 1 (extremamente dura, sem suculência e sabor extremamente desagradável) a 9 (extremamente macia, suculenta e saborosa).

Cinco amostras de cada tipo de carne foram liofilizadas para determinação da matéria seca. Após determinação da umidade, as amostras foram utilizadas para avaliação dos teores de proteína, lipídeos e cinzas (BRASIL, 1981).

O delineamento experimental adotado foi inteiramente casualizado, e os dados submetidos à análise de variância, com auxílio do pacote Statistical Package for the Social Science (SPSS, 2001) e ao teste de Correlação de Pearson, ambos a $5 \%$ de significância.

Ao se considerar a incidência de $10,06 \%$ de carcaças PSE, volume médio de 59.800 carcaças produzidas mensalmente pela indústria, peso vivo médio de abate de $115 \mathrm{~kg}$, rendimento médio de carcaça de $75 \%$, rendimento médio dos principais cortes afetados pela condição PSE, como pernil (24\%) e carré (17\%), perda de exsudato da carne PSE e normal observadas na pesquisa e o preço médio do quilograma dos referidos cortes ( $\mathrm{R} \$ 5,15)$, estimou-se o prejuízo causado mensal e anualmente à empresa pela ocorrência de carnes com baixa capacidade de retenção de água. Para estimar o montante perdido pela empresa, calculou-se a quantidade em quilogramas de pernil e carré acometidos pela anomalia PSE, a quantidade desse montante que seria perdido em forma de exsudato, se a carne fosse normal, e o montante perdido em exsudato na condição PSE. A diferença na quantidade de peso perdida na forma de exsudato entre carnes normais e PSE foi o valor considerado como prejuízo, que, por sua vez, foi multiplicado pelo preço do quilo dos cortes.

\section{RESULTADOS E DISCUSSÃO}

A incidência total de carne PSE foi de $10,06 \%$. Esse valor é inferior aos observados por outros pesquisadores, cujas porcentagens obtidas foram $22,83 \%$ (MAGANHINI et al., 2007) e 46,36\% (CULAU et al., 2002). Essa diferença pode ser explicada em virtude de muitos fatores, como genética e manejo pré-abate, estarem envolvidos no aparecimento dessa anomalia. Podese inferir também que as menores porcentagens observadas nesta pesquisa podem estar relacionadas ao fato de que as empresas de genética disponibilizam, atualmente, no mercado, muitas linhagens livres do gene halotano, bem como pelo constante aprimoramento das técnicas de manejo pré-abate, com maior conscientização em todos os segmentos da cadeia sobre os princípios de bem-estar animal e suas consequências na qualidade da carne.

Embora o pH inicial das carcaças tenha variado, o final foi semelhante nos dois tipos de carne, com média de 5,52 \pm 0,07 (Tabela 1). Ressalta-se que, o $\mathrm{pH}$ final 
Rev. Bras. Saúde Prod. Anim., Salvador, v.13, n.3, p.815-824 jul./set., 2012 http://www.rbspa.ufba.br ISSN 15199940

não é um bom indicador da condição PSE, exceto quando apresenta valores extremos $(<5,3)$ - (BOWKER et al., 1999). Em avaliação da influência do gene halotano sobre a qualidade da carne suína, Culau et al. (2002) observaram diferença entre os genótipos (NN, Nn e nn) para o $\mathrm{pH}$ inicial da carne $(5,91 ; 5,71$ e 5,68, respectivamente), entretanto, essa diferença se extinguiu após o rigor mortis, atingindo $\mathrm{pH}$ médio de 5,45, semelhante ao observado nesta pesquisa. Em contrapartida, outros pesquisadores reportaram que a diferença observada no $\mathrm{pH}$ inicial das carcaças se manteve, após atingirem o rigor mortis (LIEN et al., 2002; KUO \& CHU, 2003).

Tabela 1. Valores de $\mathrm{pH} 45$ minutos após o abate $\left(\mathrm{pH}_{45}\right), \mathrm{pH} 24$ horas após o abate $\left(\mathrm{pH}_{24}\right)$, temperatura da carcaça 45 minutos após abate $\left(\mathrm{T}_{45}\right)$ e coloração da carne suína classificadas como PSE e normal

\begin{tabular}{|c|c|c|c|}
\hline \multirow{2}{*}{ Variável } & \multicolumn{2}{|c|}{ Tipo de carne } & \multirow{2}{*}{$\mathrm{P}$ value } \\
\hline & PSE & Normal & \\
\hline $\mathrm{pH}_{45}$ & $5,64 \pm 0,09$ & $6,31 \pm 0,18$ & 0,0002 \\
\hline $\mathrm{T}_{45}$ & $39,41 \pm 1,84$ & $38,50 \pm 1,73$ & 0,106 \\
\hline $\mathrm{pH}_{24}$ & $5,50 \pm 0,07$ & $5,53 \pm 0,08$ & 0,191 \\
\hline $\mathrm{L}^{*}$ (luminosidade) & $57,12 \pm 2,42$ & $54,90 \pm 4,48$ & 0,049 \\
\hline $\mathrm{a}^{*}$ (intensidade de vermelho) & $11,17 \pm 1,48$ & $10,87 \pm 1,069$ & 0,439 \\
\hline $\mathrm{b}^{*}$ (intensidade de amarelo) & $9,01 \pm 0,85$ & $7,88 \pm 0,90$ & 0,0001 \\
\hline
\end{tabular}

Não houve diferença significativa na temperatura das carcaças aos 45 minutos após o abate, embora tenha sido quase $1^{\circ} \mathrm{C}$ superior para as carcaças dos animais classificados como PSE. Isso pode estar relacionado ao fato de que animais propensos a produzirem carne PSE são aqueles mais susceptíveis ao estresse, cujo metabolismo acelera durante as etapas do pré-abate e culmina com a elevação da temperatura corporal. A temperatura inicial das carcaças é de extrema importância nas transformações post mortem nos músculos, se considerar que a temperatura elevada do músculo, ainda na primeira hora após o abate, pode acelerar a glicólise anaeróbica e, consequentemente, queda do $\mathrm{pH}$ inicial. (BERNARDES et al., 2007).

Os valores de $L^{*}$ e $b^{*}$ foram maiores nas carnes PSE $(p<0,05)$, sem diferença observável na intensidade de vermelho $\left(a^{*}\right)$ entre os dois tipos de carne $(p>0,05)$. De acordo com alguns autores
(CHANNON et al., 2000; RAMOS \& GOMIDE, 2007), lombos suínos com valores de $\mathrm{L}^{*}{ }_{24 \mathrm{~h}}>53$ podem ser considerados PSE. Entretanto, no presente experimento, os valores de $\mathrm{L}^{*}$ tanto para as carnes PSE, quanto normais foram superiores aos mencionados por esses pesquisadores.

Cabe ressaltar a dificuldade de classificar a carne suína, ao levar em consideração o fator cor, isoladamente. Observa-se grande variação na literatura quanto aos valores de $\mathrm{L}^{*}$ considerados para carne suína normal e PSE. A American Meat Science Association (AMSA, 2001) considera valores de $\mathrm{L}^{*}$ entre 49 e 60 dentro dos padrões de qualidade da carne suína, enquanto para Ramos \& Gomide (2007) os valores de $\mathrm{L}^{*}$ de carnes normais situam-se entre 45 e 53. Os índices de vermelho obtidos foram superiores àqueles reportados por Maganhini et al. (2007), de em média 1,25 , que tampouco observaram 
diferenças entre as carnes PSE e normal para essa variável.

Foi encontrada correlação negativa $(\mathrm{p}<0,01)$ entre o $\mathrm{pH}$ inicial e os índices de $L^{*}(-0,331)-(\mathrm{p}<0,05)$ e $b^{*}(-0,528)$, o que indica que quanto menor o $\mathrm{pH}$, aos 45 minutos após o abate, mais pálida e amarela apresenta-se a carne. Não foi observada correlação entre o pH inicial e a intensidade de vermelho da carne $\left(a^{*}\right)$. Entretanto, houve correlação negativa $(\mathrm{p}<0,01)$ entre a luminosidade $\left(L^{*}\right)$ e a intensidade de vermelho $(-0,465)-(\mathrm{p}<0,01)$ e correlação positiva entre $L^{*} \mathrm{e}$ a intensidade de amarelo $\left(b^{*}\right)(0,666)$.

A palidez da carne suína é inversamente proporcional ao seu $\mathrm{pH}$. Assim como no presente experimento, Maganhini et al. (2007) encontraram correlação negativa $(\mathrm{R}=-0,46)$ entre o valor de $\mathrm{L}^{*}$ e $\mathrm{pH}_{24 \mathrm{~h}}$. e correlação positiva $(\mathrm{R}=0,43)$ entre a luminosidade e a intensidade de amarelo, o que indica que lombos mais pálidos são também mais amarelos. Ao avaliar a qualidade do músculo Longissimus dorsi de suínos, Aasling \& Barton Gade (2001) obtiveram moderada correlação negativa entre o $\mathrm{pH}$ aos 40 minutos post mortem e a luminosidade $\left(\mathrm{L}^{*}\right)$ - $(-0,36)$, o teor de vermelho $\left(\mathrm{a}^{*}\right)$ $(-0,28)$ e o teor de amarelo $\left(b^{*}\right)-(-0,32)$.

A perda de peso por cozimento e força de cisalhamento apresentaram-se semelhantes para os dois tipos de carne ( $p>0,05)$, conforme apresentado na Tabela 2. Os valores observados para a perda de peso por cocção foram próximos aos obtidos por Bridi et al. (2006) que avaliaram o efeito do genótipo halotano e do sexo sobre as características físicas da carne suína, e observaram perdas médias da ordem de 33 a $34 \%$ de água durante a cocção. Porém, os valores de força de cisalhamento, no presente trabalho, foram inferiores aos encontrados por esses autores que se mantiveram acima de $8 \mathrm{kgf}$.
A perda de exsudato foi, aproximadamente, $39 \%$ maior $(p<0,05)$ na carne PSE em relação à carne normal. Ao avaliar a qualidade de carne suína, Kuo \& Chu (2003) observaram diferenças na perda de exsudato entre carnes normais $(4,51 \%)$ e PSE $(8,34 \%)$. Lien et al. (2002) também encontraram maior perda por gotejamento em carnes PSE $(3,3 \%)$ do que em carnes normais $(1,6 \%)$, porém com valores, significativamente, menores que os observados no presente experimento.

Tabela 2. Perda de exsudato (PE), perda de peso por cozimento (PPC) e força de cisalhamento (FC) da carne suína normal e PSE

\begin{tabular}{lccc}
\hline Variáveis & $\begin{array}{c}\mathrm{PE} \\
(\%)\end{array}$ & $\begin{array}{c}\mathrm{PPC} \\
(\%)\end{array}$ & $\begin{array}{c}\mathrm{FC} \\
(\mathrm{kgf})\end{array}$ \\
\hline Normal & $6,59^{\mathrm{b}}$ & $29,12^{\mathrm{a}}$ & $5,51^{\mathrm{a}}$ \\
PSE & $9,18^{\mathrm{a}}$ & $29,48^{\mathrm{a}}$ & $6,11^{\mathrm{a}}$ \\
P value & 0,001 & 0,769 & 0,447 \\
\hline
\end{tabular}

Letras minúsculas distintas na coluna diferem pelo teste $\mathrm{F}$ ao nível de 5\% de significância.

Não foram observadas diferenças ( $>0,05)$ na composição centesimal entre as carnes PSE e normais, embora a porcentagem de proteína tenha sido superior e as de umidade e lipídeos inferiores para as carnes PSE (Tabela 3). Outros pesquisadores também observaram que lombos suínos PSE apresentaram menor porcentagem de umidade e gordura, entretanto, obtiveram maiores porcentagens de proteína do que lombos normais (KUO \& CHU, 2003). A maior perda de exsudato da carne PSE durante o armazenamento $(9,18 \% \quad \mathrm{x}$ $6,59 \%$ ) poderia explicar o fato da carne PSE apresentar maior porcentagem de matéria seca, uma vez que parte da água é perdida durante o transporte e processamento das amostras. 
Rev. Bras. Saúde Prod. Anim., Salvador, v.13, n.3, p.815-824 jul./set., 2012 http://www.rbspa.ufba.br ISSN 15199940

Tabela 3. Composição centesimal da carne suína normal e PSE (valores expressos com base na matéria natural)

\begin{tabular}{lcccc}
\hline Variáveis & Umidade (\%) & Proteína (\%) & Lipídeos (\%) & Cinzas (\%) \\
\hline Normal & 74,52 & 21,53 & 2,48 & 1,08 \\
PSE & 73,63 & 22,78 & 1,87 & 1,14 \\
\hline
\end{tabular}

Os parâmetros sensoriais avaliados não diferiram entre as carnes consideradas PSE e normais ( $p>0,05)$, ambos os tipos foram avaliados no parâmetro maciez como levemente acima da média $(6,33$ a 6,85), para suculência, no limiar entre a média a levemente acima da média $(4,60$ a 4,67), e para a variável palatabilidade, como levemente saborosa $(6,11$ a 6,33). Resultados semelhantes foram encontrados por Garcia et al. (2010), que ao avaliarem as características sensoriais de filés de peito de frango PSE e normais, não obtiveram diferenças significativas para os parâmetros avaliados entre os dois tipos de carne.

Ao avaliarem as características sensoriais da carne suína proveniente de animais de três genótipos halotano ( $\mathrm{NN}, \mathrm{Nn}$ e $\mathrm{nn}$ ), Moelich et al. (2003) encontraram diferenças significativas para suculência entre os genótipos avaliados, das quais a menor suculência observada para a carne dos animais do genótipo nn. Entretanto, não verificaram diferença para a maciez e sabor. A perda de suculência nesse caso pode ser associada à menor capacidade de retenção de água de carnes com características PSE, que no trabalho em questão estaria relacionada com a maior incidência dessa anomalia em animais com genótipo halotano recessivo. No entanto, no presente estudo, não foi verificada diferença significativa para o parâmetro suculência entre a carne PSE e normal pelos degustadores treinados.

Observou-se correlação negativa da perda de peso por cozimento com a variável sensorial suculência, e positiva com a força de cisalhamento, o que implica dizer que quanto maior a capacidade de retenção de água da carne, menor será a perda de peso ao cozimento e, consequentemente, melhor sua textura e maior sua suculência. A maciez avaliada por painel sensorial foi, negativamente, correlacionada com a perda de exsudado e força de cisalhamento (Tabela 4). A capacidade da carne em reter água está intimamente relacionada com a percepção sensorial da mesma pelo consumidor e, nesse caso, quanto maior era a perda de água, durante o armazenamento, menos maciez era detectada pelo painel de provadores. Os resultados comprovam a eficácia da avaliação da maciez da carne por meio da força de cisalhamento, uma vez que quanto maior a força de cisalhamento, menos macia foi considerada a carne pelo painel sensorial. A suculência da carne cozida é a sensação de umidade observada nos primeiros movimentos de mastigação, devido à rápida liberação de líquido pela carne e, neste estudo, foi positivamente correlacionada com a maciez e palatabilidade. Exceto para as correlações entre a força de cisalhamento e maciez, perda de exsudato e perda de peso por cozimento, as demais correlações significativas foram de baixa magnitude.

Os resultados do presente trabalho demonstram que a capacidade da carne em reter água é capaz de influenciar de forma significativa a percepção de sua qualidade pelos consumidores. 
Rev. Bras. Saúde Prod. Anim., Salvador, v.13, n.3, p.815-824 jul./set., 2012 http://www.rbspa.ufba.br ISSN 15199940

Tabela 4. Correlações entre as características da carne suína quanto perda de exsudato (PE), perda de peso por cozimento (PPC), força de cisalhamento (FC), maciez (MAC), palatabilidade (PAL) e suculência (SUC)

\begin{tabular}{lcccccc}
\hline Variável & PE & PPC & FC & MAC & PAL & SUC \\
\hline PE & - & - & - & - & - & - \\
PPC & NS & - & - & - & - & - \\
FC & $0,529 * *$ & $0,504^{* *}$ & - & - & - & - \\
MAC & $-0,397^{* *}$ & NS & $-0,767 * *$ & - & - & - \\
PAL & $\mathrm{NS}$ & $\mathrm{NS}$ & $\mathrm{NS}$ & $0,344^{*}$ & - & - \\
SUC & $\mathrm{NS}$ & $-0,326^{*}$ & $\mathrm{NS}$ & $0,297^{*}$ & $0,436^{* *}$ & - \\
\hline * $<0,05 ; * * \mathrm{p}<0,01 ; \mathrm{NS}=$ não significativo & & & &
\end{tabular}

$* \mathrm{p}<0,05 ; * * \mathrm{p}<0,01 ; \mathrm{NS}=$ não significativo

Ao considerar-se a quantidade calculada de $2.114 .528 \mathrm{~kg}$ de pernil + carré produzidos mensalmente pela indústria, o acometimento de $10,06 \%$ desses pela condição PSE, a diferença de $2,6 \%$ na perda de exsudato entre carnes normais e PSE, calculou-se que, mensalmente, a indústria deixa de ganhar aproximadamente $\mathrm{R} \$ 28.400,00$. Esse número traduz uma parcela das perdas econômicas anuais, que alcançam a ordem de $\mathrm{R} \$ 340.800,00$, em função da presença dessa anomalia.

A rápida redução do $\mathrm{pH}$ post mortem interfere na capacidade de retenção de água da carne, o que afeta, consequentemente, outras características como a sua coloração. Entretanto, na extensão ocorrida no presente experimento, essas alterações não foram suficientes para serem percebidas pelo painel de degustadores. $\mathrm{O}$ prejuízo causado às indústrias abatedouras, em função da maior perda de água nesse tipo de carne, é considerável e pode ser investido na busca por soluções para mitigar ou reduzir o problema.

\section{REFERÊNCIAS}

AASLING, M.D.; BARTON-GADE, P. Low stress pre-slaughter handling: effect of lairage time on the meat quality of pork. Meat Science, v.57, n.1, p.87-92, 2001.

\section{AMERICAN MEAT SCIENCE ASSOCIATION - AMSA. Research guidelines for cookery, sensory evaluation, and instrumental tenderness measurements of fresh meat. Chicago, 1995. 47p.}

AMERICAN MEAT SCIENCE evaluation handbook. Savoy, 2001.

ARGÜELLO, A.; CASTRO, N.; CAPOTE, J.; SOLOMON, M. Effects of diet and live weight at slaughter on kid meat quality. Meat Science, v.70, n.1, p.173-179, 2005.

BERNARDES, L.A.H.; PRATA, L.F.; PEREIRA, G.T. Eficiência da monitoração de $\mathrm{pH}$ (45min e 24h), no músculo Longissimus dorsi, na predição de atributos de qualidade da carne suína. Veterinária e Zootecnia, v.14, n.2, p.176-192, 2007. 
Rev. Bras. Saúde Prod. Anim., Salvador, v.13, n.3, p.815-824 jul./set., 2012 http://www.rbspa.ufba.br ISSN 15199940

BOWKER, B.C.; WYNVEEN, E.J.; GRANT, A.L.; GERRARD, D.E.

Effects of electrical stimulation on early post-mortem muscle ph and temperature declines in pigs from different geneticlines and halothane genotypes. Meat Science, v.53, n.2, p.125-133, 1999.

BRASIL. Ministério da Agricultura. Secretaria Nacional de Defesa Agropecuária. Laboratório Nacional de Referência Animal. Portaria n. 001/81, de 07 de outubro de 1981. Métodos analíticos oficiais para controle de produtos de origem animal e seus ingredientes. I. Métodos microbiológicos. II. Métodos físicoquímicos. Brasília, 1981.123p.

BRIDI, A.M.; OLIVEIRA, A.R.; FONSECA, N.A.N.; SHIMOKOMAKI, M.; COUTINHO, L.L.; SILVA, C.A Efeito do genótipo halotano da ractopamina e do sexo do animal na qualidade da carne suína. Revista Brasileira de Zootecnia, v.35, n.5, p.2027-2033, 2006.

CHANNON, H.A. PAYNE, A.M.; WARNER, R.D. Halothane genotype, pre-slaughter handling and stunning method all influence pork quality. Meat Science, v.56, n.3, p.291-299, 2000.

COSTA, O.A.D.; LUDKE, J.V.; COLDEBELLA, A.; KICH, J.D.; COSTA, M.J.R.P.; FAUCITANO, L.; PELOSO, J.V.; ROZA, D.D. Efeito do manejo pré-abate sobre alguns parâmetros fisiológicos em fêmeas suínas pesadas. Ciência Rural, v.39, n.3, p.852-858, 2009.

CULAU, P.O.V.; LÓPEZ, J.; RUBENSAM, J.M.; LOPES, R.F.F.; NICOLAIEWSKY, S. Influência do gene halotano sobre a qualidade da carne suína. Revista Brasileira de Zootecnia, v.31, n.2, p.954-961, 2002.
DABÉS, A.C. Propriedades da carne fresca. Revista Nacional da Carne, v.25, n.288, p.32-40, 2001.

D'SOUZA, D.N.; DUNSHEA, F.R.; WARNER, R.D.; LEURY, B.J. The effect of handling preslaughter and carcass processing rate post-slaughter on pork quality. Meat Science, v.50, n.4, p.429-437, 1998.

GARCIA, R.G.; FREITAS, L.W.; SCHWINGEL, A.W.; FARIAS, R.M.; CALDARA, F.R.; GABRIEL, A.M.A.; GRACIANO, J.D.; KOMIYAMA, C.M.; ALMEIDA PAZ, I.C.L. Incidence and physical properties of PSE chicken meat in a commercial processing plant. Revista Brasileira de Ciência Avícola, v.12, n.4, p.215-219, 2010.

KUO, C.C.; CHU, C.Y. Quality characteristics of Chinese sausages made from PSE pork. Meat Science, v.64, n.4, p.441-449, 2003.

LIEN, R.; HUNT, M.C.; ANDERSON, S.; KROPF, D.H.; LOUGHIN, T.M.; DIKEMAN, M.E.; VELZACO, J. Effects of endpoint temperature on the internal color of pork loin chops of different quality. Journal of Food Science, v.67, n.3, p.1007-1010, 2002.

MAGANHINI, M.B.; MARIANO, B.; SOARES, A.L.; GUARNIERI, P.D.; SHIMOKOMAKI, M.; IDA, E.I.

Carnes PSE (pale, soft, exudativa) e DFD (dark, firm, dry) em lombo suíno numa linha de abate industrial. Ciência e Tecnologia de Alimentos, v.27, supl.1, p.69-72, 2007.

MOELICH, E.I.; HOFFMAN, L.C.;CONRADIE, P.J. Sensory and functional meat quality characteristics of pork derived from three halothane genotypes Meat Science, v.63, n.3, p.333-338, 2003. 
Rev. Bras. Saúde Prod. Anim., Salvador, v.13, n.3, p.815-824 jul./set., 2012 http://www.rbspa.ufba.br ISSN 15199940

ORDOÑEZ, J.A.; CAMBERO, M.I.; FERNANDEZ, L.; GARCIA, M.L.; GARCIA DE FERNANDO, G., HOZ, L. y SELGAS, M.D. In: ORDOÑEZ, J.A. (Ed.). Tecnología de los alimentos: alimentos de origen animal. Madrid: Síntesis, 1998. v.2, p.169-186.

PÉREZ, M.P.; PALACIO, J.; SANTOLARIA, MP.; ACEÑA, M.C.; CHACÓN, G.; VERDE, M.T.; CALVO, J.H.; ZARAGOZA, M.O.; GASCÓN, M.; GARCÍA-

BELENGUER, S. Influence of lairage time on some welfare and meat quality parameters in pigs. Veterinary Record, v.33, p.239-250, 2002a

PÉREZ, M.P.; PALACIO, J.; SANTOLARIA, MP.; ACEÑA, M.C.; CHACÓN, G.; GASCÓN, M.; CALVO, J.H.;. ZARAGOZA, M.O.; BELTRAN, J.A.; GARCÍA-BELENGUER, $S$. Effect of transport time on welfare and meat quality parameters in pigs. Meat Science, v.61, p.425-433, 2002 b.

RAMOS, E.M.; GOMIDE, L.A.M. Avaliação da qualidade de carnes: Fundamentos e Metodologias. Viçosa, MG, Ed. UFV, 2007. 599 p.
SATHER, A.P., JONES, S.D.M., TONG, A.K.W. Halothane genotype by weight interactions on pig meat quality. Canadian Journal of Animal Science, v.71, n.3, p.645-658, 1991.

SIQUEIRA, E.R.; ROÇA, R.O.; FERNANDES, S.; UEMI, A.

Características sensoriais da carne de cordeiros da raça Hampshire Down, Santa Inês e mestiços Bergamácia $\mathrm{x}$ Corriedale abatidos com quatro distintos pesos. Revista Brasileira de Zootecnia, v. 31, n.3, p.1269-1272, jun. 2002.

SPSS Inc. Statistical Analysis Using SPSS. Version 13. Chicago, 2001.

VELAZCO, J. Prevención de PSE en carne de cerdo. Carne Tec, v.8, p.28-34, 2001.

Data de recebimento: 16/08/2011

Data de aprovação: 27/05/2012 